\title{
RELAÇÕES ENTRE DIMENSÕES DA EXPERIÊNCIA, SATISFAÇÃO, RECOMENDAÇÃO E INTENÇÃO DE RETORNAR: A PERCEPÇÃ̄O DE PARTICIPANTES DE EVENTO CULTURAL RESUMO
}

\author{
${ }^{1}$ Raquel Lobuono \\ 2 Marlusa de Sevilha Gosling \\ ${ }^{3}$ Carlos Alberto Gonçalves \\ ${ }^{4}$ Sandro Alves Medeiros
}

\section{RESUMO}

A experiência de consumo ganhou importância na área de marketing nas últimas décadas. No entanto, a mensuração dessa dimensão ainda é recente e restrita em relação a sua aplicabilidade. Diversos autores elaboraram escalas que medem a experiência de consumo no contexto das marcas, eventos esportivos e eventos turísticos. Os eventos podem ser utilizados como meio de promoção das experiências porque os consumidores têm a chance de se envolver em atividades que não são possíveis nas suas vidas diárias. $\mathrm{O}$ evento objeto de estudo do presente trabalho é a Virada Cultural 2014 de Belo Horizonte, evento cultural realizado pela segunda vez consecutiva na capital mineira durante um final de semana. $\mathrm{O}$ estudo buscou compreender as experiências dos participantes da Virada Cultural a partir de uma escala de experiência memorável turística elaborada e testada em outro trabalho. Para isso, foi realizada uma pesquisa de caráter descritivo com uma abordagem quantitativa por meio a aplicação de um survey durante o evento. Os principais resultados foram (1) a dimensão hedonismo foi a mais impactante para Experiência Memorável e a Cultura Local como a menos impactante; (2) a relação positiva e significante entre Experiência Memorável e satisfação e (3) a relação positiva e significante entre Satisfação e Intenção de Retorno nas próximas edições e a Recomendação boca a boca para pessoas próximas.

Palavras-chave: Experiência de consumo; Satisfação do consumidor; Intenção de retorno; Recomendação boca a boca.

\footnotetext{
${ }^{1}$ Graduada em Administração pela Universidade Federal de Minas Gerais - UFMG, Belo Horizonte Minas Gerais, (Brasil). E-mail: rlobuono@gmail.com

${ }^{2}$ Doutora em Administração pela Universidade Federal de Minas Gerais - UFMG, Belo Horizonte Minas Gerais, (Brasil). Professora Associada de Marketing e Turismo do CAD/CEPEAD/UFMG. E-mail: mg.ufmg@gmail.com

${ }^{3}$ Doutor em Administração pela Universidade de São Paulo - USP, São Paulo, (Braisl). Professor da Universidade Federal de Minas Gerais - UFMG, Belo Horizonte Minas Gerais, Brasil. E-mail: carlos@face.ufmg.br

${ }^{4}$ Mestre em Administração pela Universidade Federal de Alagoas - UFAL, (Brasil). Professor da Universidade Federal de Alagoas E-mail: sandroamedeiros@gmail.com
} 


\title{
RELATIONSHIP BETWEEN DIMENSIONS OF EXPERIENCE, SATISFACTION, WORD-OF-MOUTH AND INTENTION TO RETURNING: THE PERCEPTION OF CULTURAL EVENT PARTICIPANTS
}

\begin{abstract}
Consumer experience has gained importance in marketing in recent decades. However, measurement of that dimension regarding its applicability is still new and insufficient. Several authors have developed scales for measuring consumer experience in the context of brands, sports and tourism. Events can be used as a path to promoting experiences, because consumers have the chance to engage in activities that are not usual in their daily lives. The object of this paper is to study the Virada Cultural de Belo Horizonte 2014, a cultural event held for the second time in Belo Horizonte. The study aimed to understand the experiences of participants at Virada Cultural from a range of dimensions of memorable tourist experiences already tested. For this, we held a descriptive research with a quantitative approach through the application of a survey during the event. The main results were: (1) hedonism dimension was the most influencing factor to Memorable Experience while Local Culture was the least influencing one; (2) there is positive and significant relationship between Memorable Experience and Satisfaction, and (3) there is positive and significant relationship between Satisfaction and Intention to Returning and Word-of-Mouth recommendation.
\end{abstract}

Keywords: Consumer experience; Customer satisfaction; Intention to returning; Word-ofmouth recommendation. 


\section{INTRODUÇÃO}

$\mathrm{Na}$ forma de rituais, os eventos sempre desempenharam papel significativo na História da humanidade, por contribuir na formação e sustentação dos povos e por incutir crenças, estabeler ordem, estrutura e manter costumes e tradições, além de transmitir e impor valores (Moufakkir; Pernecky, 2015).

Os eventos, de uma forma geral, e os festivais, de modo particular, promovem uma "efervescência coletiva", servindo como canais para a expressão e consolidação de um sentido de comunidade (Giorgi, Sassatelli e Delanty, 2011). Nos dias de hoje, os eventos são reconhecidamente um dos aspectos da globalização da sociedade, com múltiplas características que se refletem nos espaços físicos e na sociedade (Paiva, 2015).

Assim, os eventos permeiam a vida em sociedade há milênios e fazem parte do cotidiano, desde os pequenos eventos em família, como aniversários, casamentos, formaturas, marcando rituais de passagem (Van Gennep, 2011), passando pelas comemorações anuais, como Dia das Mães, dos Pais, Natal, Páscoa etc., os encontros educacionais e profissionais, conferências, cursos, todos relacionados à vida na escola, universidade e trabalho, até os eventos de entretenimento mais comuns ou mesmo inusitados, como concertos, shows, festivais etc.

Do ponto de vista do turismo, independentemente do tipo, se esportivo, cultural, político, histórico, religioso ou comercial, com foco em negócios, os eventos oferecem oportunidades para os participantes terem experiências memoráveis e aumento das atividades de turismo e negócios (Hede \& Kellet, 2011). Uma viagem de negócios, por exemplo, é complementada com atividades de lazer e turismo nas horas livres (Paiva, 2015).

Nesse contexto, o objeto de estudo deste trabalho corresponde a um evento cultural: a Virada Cultural de Belo Horizonte de 2014. Tal evento cultural aconteceu pelo segundo ano consecutivo na capital mineira, durante vinte e quatro horas, com início no dia 30 de agosto, sábado às 19 h00 e término no dia 31 de agosto, domingo, às $19 \mathrm{~h} 00$. Ele promoveu mais de 450 atividades culturais em 62 espaços na cidade (Virada Cultural de Belo Horizonte, 2014). Em 2013, contou com cerca de 200 mil pessoas e, em 2014, cerca de 350 mil pessoas participaram da Virada (G1 MG, 2014). A Virada Cultural acaba por, consequentemente, promover o turismo de eventos, que é definido por Paiva (2015, p. 486) como "uma segmentação que possui como produto turístico a realização de um acontecimento planejado, que constitui uma importante motivação para o desenvolvimento da atividade turística".

$\mathrm{O}$ evento ofereceu manifestações artísticas ligadas à música, teatro, cinema, dança, literatura, artes plásticas, circo e intervenções urbanas. Assim, a Virada Cultural foi produzida no intuito de proporcionar o encontro de pessoas, experiências culturais para diferentes públicos, por meio da reunião de artistas de diferentes origens e da população de Belo Horizonte e região. A Virada Cultural, assim como outros eventos culturais, utilizou os espaços públicos da cidade (praças, parques e ruas) transformando esses locais e atraindo a população local além dos turistas (Paiva, 2015).

Tendo em vista a importância das investigações sobre a experiência de consumo no comportamento do consumidor de serviços, que ainda são recentes e requerem mais estudos, os objetivos principais deste trabalho são: (i) verificar os aspectos da experiência que foram antecedentes à satisfação do consumidor na Virada Cultural em Belo Horizonte de 2014 e (ii) as relações causais entre os aspectos da experiência, a satisfação e as intenções 
de retorno e de recomendação nesse contexto. Nesse sentido, as perguntas de pesquisa que norteiam este estudo são: quais dimensões da experiência influenciaram a satisfação do consumidor na Virada Cultural em Belo Horizonte de 2014? Como se dão as relações entre os aspectos da experiência, a satisfação do participante e as intenções de retorno e de recomendação no contexto da Virada Cultural de Belo Horizonte 2014?

Para alcançar os objetivos de pesquisa, o estudo se baseou no modelo teórico proposto por Kim, Ritchie e Mccormick (2010) para investigação de experiências turísticas memoráveis (MTE). Embora o trabalho de Kim, Ritchie e Mccormick (2010) tenha sido desenvolvido no âmbito do turismo, o presente estudo utilizou esse modelo teórico no contexto de um evento cultural porque considera que tal modelo traz uma contribuição às pesquisas sobre consumo ao explorar a questão da experiência, sobretudo como antecedente à satisfação. Além disso, o conceito da experiência tornou-se um ponto importante para a investigação sobre o gerenciamento da satisfação dos consumidores.

\section{REFERENCIAL TEÓRICO}

\section{Experiência de Consumo}

O conceito de Experiência de Consumo geralmente é associado ao brand experience que acompanha as ações de marketing, buscando criar uma conexão da marca com os clientes. Com base nessa visão ampla, as experiências podem ser originadas por produtos, embalagens, comunicações, interações, relações de venda, eventos e afins (Gilmore \& Pine, 1999). Os autores definem que a experiência ocorre quando uma empresa intencionalmente usa serviços como palco, e produtos como enfeites, para envolver os clientes individuais de uma forma que ofereça um evento memorável.
$\mathrm{Na}$ concepção de Gilmore e Pine (1999), vive-se hoje a economia da experiência, na qual os consumidores desejam viver experiências, e não apenas adquirir um produto ou um serviço. A economia da experiência é resultante de um processo evolutivo na cadeia de oferta econômica, que no seu estágio mais elementar oferta produtos sem qualquer diferenciação, as commodities, e, com o tempo, alcança estágios superiores, aumentando-se o grau de diferenciação e reduzindo-se o de tangibilidade. Assim, das commodities (bens fungíveis), a economia evoluiu para os produtos diferenciados (bens tangíveis), daí para os serviços (intangíveis) e finalmente para as experiências (Gilmore \& Pine, 1999).

A partir de uma perspectiva gerencial, Schmitt (1999) apresenta o marketing de experiência, que teria como objetivo criar experiências sensoriais, afetivas, cognitivas, criativas, comportamentais e sociais para o consumidor, a fim de aumentar seu vínculo com a marca e a organização.

$\mathrm{Na}$ literatura do turismo, Oh, Fiore e Jeong (2007) desenvolveram um instrumento de mensuração (questionário) que se baseia na escala e nos conceitos definidos por Pine e Gilmore (1998), considerando as quatro dimensões de experiências: estética, educação, entretenimento e escapista. Os autores demonstraram que os quatro domínios de experiências são válidos para análise de experiências no contexto do turismo.

Oh, Fiore e Jeong (2007) afirmam que a economia da experiência já pertence à literatura do turismo, entretanto ainda é necessária a realização de muitas pesquisas para compreender os componentes e características das experiências turísticas. Em seu estudo, os pesquisadores propõem que o turista é motivado pela "préexperiência" a partir de suas expectativas acerca da viagem e do destino. No

processo de geração de expectativas são formadas imagens mentais e emocionais intensas acerca do destino, negligenciando- 
se suas reais características físicas. A conclusão dos autores é que as memórias podem ser definidas como mecanismos de seleção, que conectam as experiências vividas com os pensamentos emocionais e expectativas de um evento turístico.

Brakus, Schmitt e Zarantonello (2009) estudaram várias dimensões de experiência e propuseram uma escala que inclui quatro dimensões: sensorial, afetiva, intelectual e comportamental. Em seu estudo, os autores mostram que o constructo experiência (de marca) se distingue de outros conceitos relacionados ao comportamento do consumidor com a marca, tais como avaliação de marca, envolvimento com a marca, apego à marca, satisfação e personalidade de marca.

Apesar da importância e da urgência por estudos sobre experiências memoráveis (ME), relativamente poucos trabalhos exploraram os componentes da experiência que são mais propensos a serem recordados. Além disso, as pesquisas ficaram restritas à análise de apenas alguns sentimentos afetivos, tais como sociabilidade, prazer, felicidade, irritação, culpa. Em um contexto mais próximo, do turismo, Kim, Ritchie e Mccormick (2010) buscaram analisar os fatores que caracterizam as experiências turísticas memoráveis.

Como Kim, Ritchie e Mccormick (2010) demonstraram, as primeiras pesquisas sobre a experiência avançaram até o ponto em que satisfação e qualidade por si só não são descrições mais adequadas da experiência que os turistas atualmente procuram. Na literatura sobre memória, os pesquisadores descobriram vários fatores que aumentam a recordação de um evento. Estes incluem sentimentos afetivos, avaliações cognitivas e novidade. Os pensamentos afetivos são uma importante parte da memória, e os eventos

que estão relacionados às emoções são mais propensos a serem lembrados. No estudo desses autores foram propostas sete dimensões de experiência turística memorável: hedonismo, renovação, cultura local, envolvimento, significância, conhecimento e novidade.

O hedonismo é uma característica imprescindível nas experiências de lazer (Otto \& Ritchie, 1996) e um fator crucial na determinação da satisfação dos turistas, bem como no seu comportamento futuro (Dunman \& Mattila, 2005). Na experiência turística memorável, o hedonismo refere-se à emoção, ao prazer e à participação em atividades (Kim, Ritchie \& Mccormick, 2010). Já a dimensão renovação está ligada à sensação revigoramento, quando alguém se sente rejuvenescido, renovado, pronto para lidar com alguma situação ou se sentindo capaz de realizar algo (Howard, Tinsley, Tinsley \& Holt, 1993).

O construto cultura local possui conexão direta com a experiência turística, já que está presente na interação dos visitantes com a população local. Atributos tais como as atitudes, as competências, a organização envolvida na atividade turística, inovação, simpatia da população local, entre outros, se mostram importantes na escolha de um lugar turístico (Murray, Foley \& Lynch, 2010).

Quanto mais as pessoas demonstram envolvimento com o lugar escolhido para a viagem e com as atividades das quais escolheram participar, torna-se mais provável a recordação e a recuperação das memórias das experiências da viagem. Os consumidores altamente envolvidos estão mais propensos a reagir em relação a coisas muito boas ou muito ruins em suas experiências, uma vez que experimentam e sentem tais situações de forma mais intensa (Kim, 2009).

A dimensão significância da experiência turística memorável reflete os Benefícios advindos da participação em atividades de turismo, que melhoram o humor e elevam o bem-estar, permitindo que os turistas descubram mais sobre a própria identidade e aprendam sobre outros lugares e culturas (Kim, Ritchie \& Mccormick, 2010). A significância de uma experiência é uma das maneiras pelas quais as pessoas encontram significado através 
das experiências de turismo (Bruner, 1991; Noy, 2004).

As pessoas desejam também participar de atividades e experiências diferentes, especialmente aquelas atividades em que exploram seus talentos e capacidades (Otto \& Ritchie, 1996). De acordo com Kim, Ritchie e Mccormick (2010), o conhecimento pode ser definido como informações, fatos ou experiências conhecidas por um indivíduo.

A sétima dimensão da experiência turística memorável é a novidade. Farber e Hall (2007) consideram que experiências carregadas de emoções muitas vezes estão associadas a eventos inesperados, novos e/ou surpreendentes. Nesse sentido, novidade é uma dimensão que deve ser levada em consideração quando há a intenção de entender a satisfação e a qualidade percebida pelo participante de uma experiência turística. O estudo desses autores mostrou que as experiências extraordinárias vividas pelas pessoas estavam normalmente associadas a algo novo, original ou inesperado.

\section{Satisfação do Consumidor}

Pesquisas anteriores demonstraram que a satisfação pode afetar atitudes e criar mudanças de atitude (OLIVER, 1980). A satisfação com o consumo pode influenciar na atitude de repetir o uso de um mesmo produto e/ou serviço, assim como a insatisfação pode gerar a mudança de atitude, por meio da busca por outras marcas ou a escolha de não utilizar mais aquele produto ou serviço.

Segundo Oliver (1980), a satisfação do consumidor ocorre a partir do

julgamento experiencial dos resultados em relação a um conjunto de metas ou padrões, resultando em uma sensação de realização com a superação de expectativas ou com a frustração de satisfação incompleta. A satisfação é expressa como uma função de expectativas pré-compra e pós-compra em comparação com o desempenho percebido do respectivo produto ou serviço. A partir dessa definição, o autor propõe o paradigma da desconfirmação: quando o consumidor tem sua expectativa alcançada, confirmada, está satisfeito. Se as expectativas são superadas, o consumidor se sentirá "encantado", o estágio máximo de satisfação. A insatisfação é gerada pela confirmação de que a realidade não corresponde ao esperado. Assim, Oliver (1997) propõe que a satisfação é uma característica subjetiva do consumidor na escolha do produto ou serviço, relacionada com um nível prazeroso de realização com o consumo.

Diferentes fatores são utilizados por consumidores na sua determinação dos níveis de satisfação para diferentes produtos e serviços. O mais importante é que diferentes atributos têm diferentes níveis de importância na determinação global do nível de satisfação dos clientes com uma experiência de serviço (CRONIN; TAYLOR, 1992). Portanto a satisfação do consumidor com determinado evento depende inteiramente do que está sendo avaliado naquela determinada experiência.

A lealdade do cliente refere-se a um compromisso profundamente relacionado à recompra de um produto ou serviço no futuro, apesar de existirem as influências situacionais e esforços de marketing de diferentes concorrentes para causar um comportamento de preferência (OLIVER, 1997). Além da expectativa, Oliver (1997) afirma que o desempenho, a atribuição (local, estabilidade e capacidade de controle), a equidade (justiça e preferência) e as emoções são determinantes possíveis da satisfação.

Além disso, o autor propõe que a satisfação também pode ser distinguida pelo grau de envolvimento do consumidor, sendo ele ativo ou passivo. Quando os resultados são comparados com os esforços ou atividades do consumidor, ocorre engajamento ativo. Quando os resultados são comparados com os padrões preexistentes, incluindo as expectativas ou 
desejos, o envolvimento passivo é mais evidente.

Dessa forma, o nível de satisfação dos participantes de uma experiência é baseado em uma comparação de suas expectativas de previsão para o que vai ocorrer nessa experiência de serviço com suas percepções do que realmente ocorre (Chen; Tsai, 2007).

$\mathrm{Na}$ literatura voltada para o turismo, a satisfação demonstrou ser um forte preditor de intenções comportamentais na fase pósexperiência turística (Baker; Crompton, 2000), quando os indivíduos avaliam de forma mais ampla a experiência vivenciada. A satisfação demonstrou mediar parcialmente os impactos da qualidade do serviço sobre as intenções e atitudes comportamentais (Ekinci, 2004).

\section{Intenção de Retorno}

Segundo Ajzen e Fishbein (1980), a intenção é o maior indicador da existência ou não de um comportamento específico. Para os autores, em geral os indivíduos terão a intenção de realizar um comportamento quando avaliá-lo positivamente e acreditarem que outras pessoas também considerarem esse comportamento importante. A teoria de Ajzen e Fishbein (1980) parte do princípio de que a atitude é formada através da aprendizagem cognitiva: após ter contato com o objeto ou receber uma nova informação por meio da interação social, a pessoa forma crenças, a partir das quais avalia afetivamente e, então, uma atitude é mudada ou uma nova atitude é criada.

No Modelo da Ação Racional (Ajzen e Fishbein, 1980), a componente cognitiva da atitude (as crenças) é vista como a mais influente no processo de avaliação do objeto e também como antecedente de outros fatores, quando se avaliam eventos/pessoas ou situações. A Teoria da Ação Racional é um modelo para a previsão da intenção comportamental, abrangendo previsões de atitude e previsões de comportamento. A separação da intenção comportamental do comportamento permite a explicação dos fatores limitantes sobre a influência da atitude (Ajzen e Fishbein, 1980). O modelo desenvolvido pelos autores está descrito na figura 1.

Figura 1 - Modelo da Ação Racional

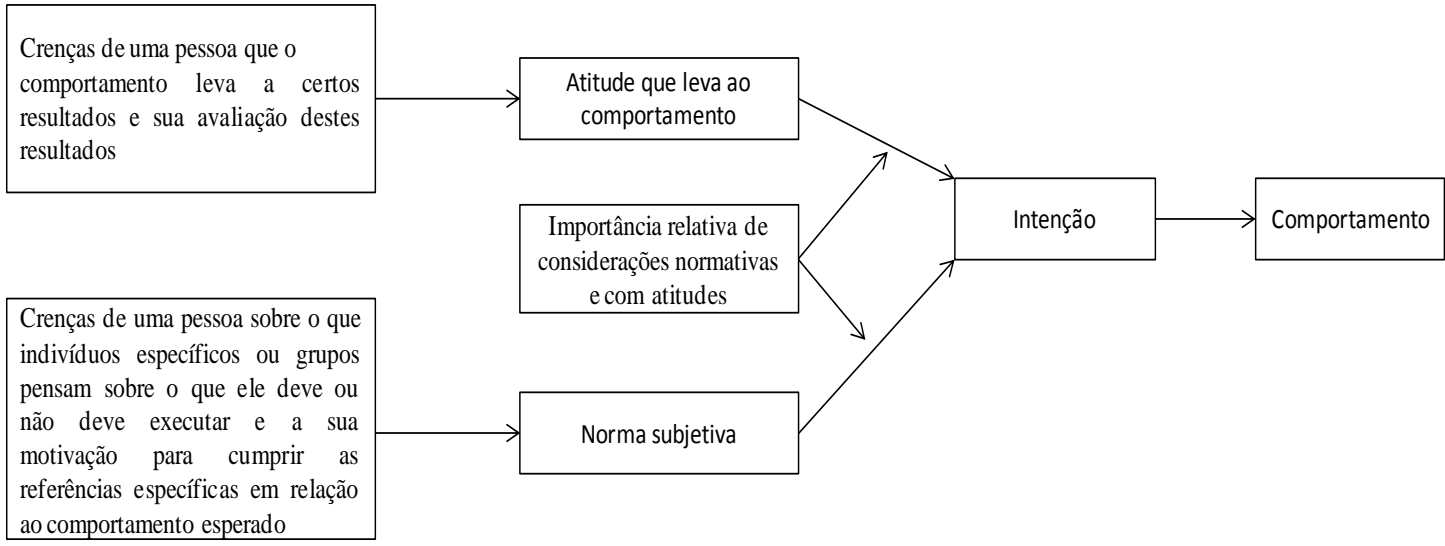

Fonte: Adaptado de Ajzen \& Fishbein (1980)

A intenção comportamental mede a intenção de uma pessoa de realizar um comportamento. A atitude é constituída de crenças sobre as consequências da realização do comportamento a partir da avaliação dessas consequências. A norma subjetiva é vista como uma combinação de expectativas percebidas de indivíduos ou 
grupos, juntamente com a intenção de cumprir essas expectativas relevantes. Em outras palavras, a percepção da maioria das pessoas que são importantes para um indivíduo sobre o que ele deve ou não realizar define o comportamento final em questão (Ajzen \& Fishbein, 1980). Em termos simples: o comportamento de uma pessoa é predito pela sua atitude em relação a esse comportamento e sua crença em como outras pessoas o julgarão, caso ele realize o comportamento. A atitude de uma pessoa, combinada com normas subjetivas, forma sua intenção comportamental.

Ambas as teorias defendidas pelos autores, Teoria da Ação Racional e Teoria do Comportamento Planejado, assumem que o comportamento é o resultado de uma decisão consciente de agir de uma determinada maneira. No entanto, existe uma diferença fundamental entre as duas teorias. Ao contrário da Teoria da Ação Racional, que é utilizada apenas para comportamentos sob o controle de uma pessoa, a Teoria do Comportamento Planejado considera o controle a partir da vontade como uma variável. A pessoa deve ter recursos, oportunidades e apoio disponível para realizar um comportamento específico (Ajzen, 1991).

Embora não haja uma perfeita relação entre intenção comportamental e o comportamento real, a intenção pode ser usada como medida substituta do comportamento. Essa observação é uma das contribuições mais importantes do modelo.

A experiência passada ou o comportamento anterior também foram identificados como um atributo significativo do comportamento futuro. Ajzen (2002) discutiu extensivamente o papel importante do comportamento passado dentro da Teoria do Comportamento Planejado. O comportamento passado reduz os riscos percebidos associados a decisões relacionadas a determinados produtos ou serviços e, consequentemente, pode influenciar positivamente a intenção de consumir um serviço ou um produto novamente ou adquirir um novo.

\section{Recomendação boca a boca}

Embora raramente existam estudos dedicados a analisar o efeito da motivação da recomendação boca a boca no contexto de eventos culturais, seu impacto tem sido bem estabelecido em outras disciplinas, como marketing, turismo e hospitalidade (Yoon e Uysal, 2005). Por exemplo, em seu estudo do turismo, Yoon e Uysal (2005) constataram que a motivação dos viajantes (desejos intangíveis ou intrínsecos do viajante individual para o escapismo e o relaxamento) foi positivamente relacionada a recomendações sobre o destino. No estudo realizado com passageiros de cruzeiros, Hung e Petrick (2010) verificaram que as motivações para viajar novamente em outro cruzeiro dependiam das referências positivas que tinham de outras pessoas (ou seja, recomendação boca a boca). Os resultados de pesquisas anteriores têm sido consistentes em mostrar que as motivações de consumo impactam positivamente os comportamentos de consumo na recomendação boca a boca e intenção de revisitar (Kim e Byon, 2013).

A satisfação do cliente é um forte condutor da recomendação boca a boca, e, por sua vez, pode influenciar as decisões de consumo, expectativas, atitudes antes do consumo e as percepções após o consumo (Ranaweera e Jayawardhena, 2014). A interatividade, a velocidade e a falta de viés comercial da recomendação boca a boca fizeram do recurso uma fonte eficaz de informações sobre consumidores em potencial, particularmente no que diz respeito aos serviços, em que a experiência pré-compra pode ser limitada (East et al., 2007).

No contexto das interações de serviço, ou no caso do presente estudo, um evento cultural, a variabilidade de percepções de consumo, assim como das atrações 
presentes nesse cenário, faz com que as pessoas possam sempre encontrar pontos positivos e negativos sobre suas experiências. Tais experiências podem influenciar os indivíduos a modificar seu depoimento sobre o evento para melhorar a sua identidade social (Ranaweera e Jayawardhena, 2014).

Quando os consumidores não têm percepções claras sobre um serviço, tendem a usar as informações disponíveis no ambiente, o que ocorre por meio do que ouvem de outros. Portanto, a incapacidade dos consumidores para avaliar a credibilidade de um evento torna-os mais propícios a serem influenciados pelo que os outros dizem, e quando eles não estão totalmente satisfeitos esse efeito é ainda mais forte. Quando os consumidores têm dificuldade para avaliar o serviço que recebem, qualquer recomendação positiva em relação a outro serviço concorrente (nesse caso, a comparação com um evento que tenha uma recomendação positiva melhor) não só leva às pessoas a recomendarem o evento de forma negativa, mas também reforça o efeito de insatisfação (Ranaweera e Jayawardhena, 2014).

A recomendação boca a boca muitas vezes ocorre em contextos sociais entre amigos e familiares que possuem uma forte afinidade uns com os outros. Em tais contextos, as interações sociais se tornam um cenário importante para a ocorrência da recomendação boca a boca (Ranaweera e Jayawardhena, 2014). Chen e Chen (2010) verificaram que a intenção futura de um indivíduo depende de sua intenção de recompra e intenção de dar recomendações positivas. A fidelização, caracterizada a partir da satisfação de consumo em longo prazo, provoca a vontade de recomendar a experiência para pessoas próximas e, no caso de contextos turísticos, garante a intenção de revisitar o destino. Os consumidores satisfeitos estão propensos a voltar e recomendar o serviço a amigos e parentes.

No âmbito do turismo, e no contexto cultural em que este estudo se dá, a modelagem da intenção de recomendar continua a ser uma importante área de pesquisa. Os níveis de satisfação dos turistas estão intimamente associados com essa intenção comportamental (Hosany e Gilbert, 2009). O estudo evidencia a associação direta entre as dimensões emocionais da experiência, satisfação e intenção dos turistas para recomendar sua vivência. As análises revelam que a satisfação tem o papel mediador entre as emoções presentes nas experiências e a intenção de recomendação boca a boca.

\section{METODOLOGIA}

O modelo de pesquisa proposto para o presente estudo considerou a relação entre a experiência turística memorável (escala proposta por Kim, Ritchie e Mccormick, 2010), satisfação do consumidor (escala baseada em Oliver, 2007), intenção de retorno (escala baseada em Ajzen \& Fishbein, 1980) e de recomendação boca a boca (escala baseada em Yoon \& Uysal, 2005).

O modelo de pesquisa proposto buscou identificar a relação entre as variáveis de acordo com a literatura com foco na experiência de consumo. Na figura abaixo segue o modelo do estudo considerando os construtos propostos por Kim, Ritchie e Mccormick (2010) como pincipais dimensões da experiência memorável. 


\section{Figura 1 - Modelo de pesquisa}

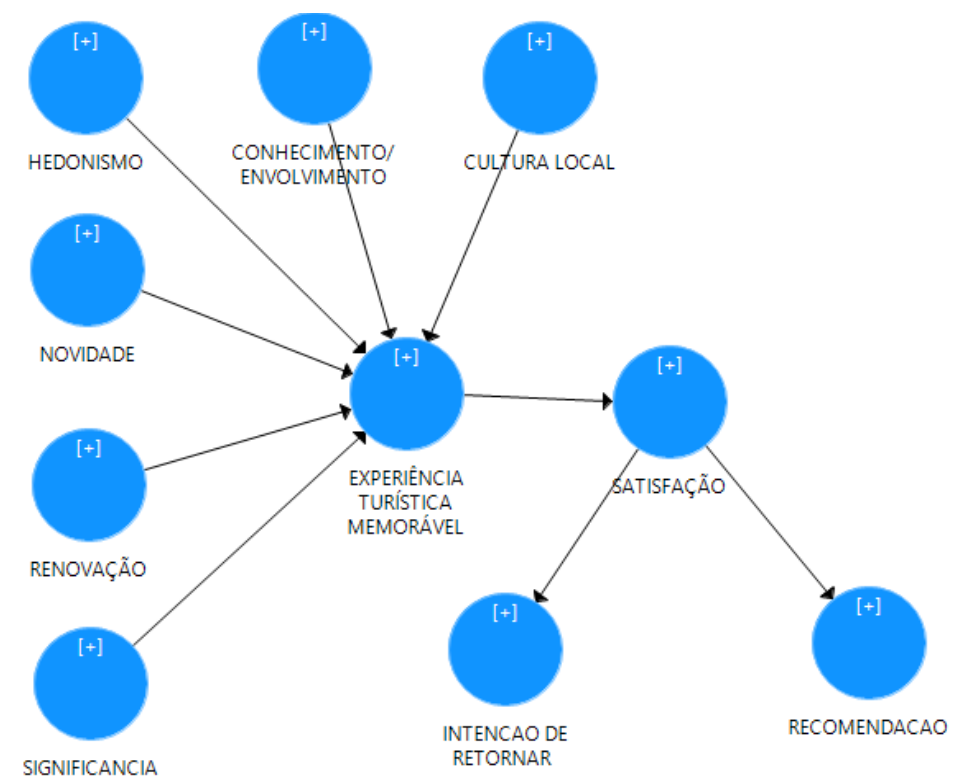

Fonte: Adaptado de Kim, Ritchie e Mccormick (2010).

As hipóteses testadas pelo modelo de pesquisa foram:

H1: Cultura Local influencia positivamente a Experiência Turística Memorável;

H2: Conhecimento influencia positivamente a Experiência Turística Memorável;

H3: Envolvimento influencia positivamente a Experiência Turística Memorável;

H4: Hedonismo influencia positivamente a Experiência Turística Memorável;

H5: Novidade influencia positivamente a Experiência Turística Memorável;

H6: Renovação influencia positivamente a Experiência Turística Memorável;

H7: Significância influencia positivamente a Experiência Turística Memorável;

H8: Experiência Turística Memorável influencia positivamente a Satisfação como evento;

H9: Satisfação influencia positivamente a Intenção de Retornar ao evento;

H10: Satisfação influencia positivamente a Recomendação sobre o evento.

Esta pesquisa segue abordagem quantitativa, que, segundo Creswell (2007), é um meio para testar hipóteses, examinando a relação entre variáveis. Essas variáveis devem ser medidas por instrumentos, escalas, para que os dados 
numéricos possam ser analisados por procedimentos estatísticos (Creswell, 2007).

O presente estudo é descritivo, porque busca testar relações entre variáveis testadas em um contexto novo: a Virada Cultural. A escala utilizada no survey assim como as relações presentes no modelo de pesquisa já foram confirmadas e exploradas em ambientes como eventos esportivos e turísticos, mas este trabalho busca verificar as relações no evento Virada Cultural em Belo Horizonte.

Dessa forma, um survey foi realizado com pessoas que estavam presentes no evento Virada Cultural, na capital (Belo Horizonte) do estado de Minas Gerais, no Brasil.

A amostra utilizada caracterizou-se como não probabilística por conveniência. A escolha da amostra é feita de acordo com as pessoas mais disponíveis e que se enquadram na população definida, além de terem disponibilidade para fornecer informações para o estudo (Cozby, 2003). Assim, a pesquisa foi realizada em seis lugares diferentes onde aconteceram atrações do evento, alcançando-se um total de 128 entrevistados, sendo que 10 desses respondentes não concluíram o questionário ou suas respostas apresentaram viés. Com isso, a amostra consistiu em 118 sujeitos. O período de coleta de dados se deu, portanto, durante os dias em que a Virada Cultural foi promovida - 30 e 31 de agosto de 2014.

O questionário da pesquisa foi baseado no questionário desenvolvido por Kim, Ritchie e Mccormick (2010) em seu modelo de mensuração de experiências turísticas memoráveis. A escala teve

adaptação de alguns itens, considerando expressões em português que melhor definem os significados apresentados na escala em inglês. A adaptação dos itens foi avaliada e revisada por um grupo de pesquisadores da área de marketing. Notese que a Experiência Memorável foi modelada como um construto de segunda ordem, ou seja, testou-se um modelo hierárquico (Hair et al., 2015).
Além disso, foram acrescentadas perguntas referentes ao nível de satisfação com o evento, intenção de retorno e recomendação boca a boca ao final do questionário para testar a relação dessas dimensões com os construtos de experiência.

O questionário é composto por 30 perguntas e afirmativas fechadas, sendo 24 referentes à escala definida por Kim, Ritchie e Mccormick (2010), quatro referentes à intenção de retorno dos participantes, uma referente à satisfação do participante com o evento e uma referente à recomendação boca a boca do evento para pessoas próximas. Todas as perguntas e afirmativas foram mensuradas segundo uma escala intervalar do tipo Likert de 11 pontos. Os itens podem ser verificados na Tabela 1.

Primeiramente, os dados coletados foram preparados para análise. Alguns questionários tiveram que ser retirados da amostra porque apresentaram dados incompletos, ou porque os respondentes marcaram a mesma opção para todas as perguntas. $\mathrm{O}$ modelo foi testado usando Modelagem por Equações Estruturais, com o apoio dos softwares (1) Spss e Excel, para análise de outliers, de linearidade, de normalidade e unidimensionalidade e (2) SmartPLS, para Equações Estruturais. Esse software foi escolhido por exigir a normalidade multivariada dos dados e também pelo tamanho relativamente pequeno da amostra.

\section{RESULTADOS}

\section{Analise de Outliers Uni e Multivariados, Lineraridade e Normalidade}

Para identificar outliers uni e multivariados, seguiu-se o recomendado por Hair et al. (2005). Segundo os autores, para encontrar outlier univariado em amostras superiores a 80 observações, o valor básico de escores-padrão deve variar entre 3 e 4 . A análise de outlier multivariado 
foi baseada no cálculo de Mahalanobis $\left(\mathrm{D}^{2}\right)$ dividido pelo grau de liberdade. $\mathrm{O}$ parâmetro utilizado para a definição de um outlier foi o de Hair et al. (2014), que considera outlier as observações que apresentarem valores acima de 2,5 (amostras pequenas), 3,5 ou 4 (amostras grandes). Seguindo o critério proposto por Hair et al. (2014), nenhum caso de outlier uni ou multivariado foi identificado.

Para testar a linearidade, calculou-se a correlação linear par a par, utilizando-se a correlação de Spearman. Esse método foi utilizado por ser não paramétrico, uma vez que os dados apresentaram ausência de normalidade. Por fim, as correlações significativas indicam a presença de dados lineares. Desse modo, 99\% dos dados apresentaram correlações significativas no nível de $1 \%$.

A análise da normalidade dos dados foi feita baseada na curva de distribuição normal, comparando os dados da amostra com uma distribuição normal com a mesma média e mesmo desvio padrão (HAIR et al., 2014). O teste de Kolmogorov-Smirnov é indicado para amostras superiores a 50 (Souza, 2013). Desse modo, a análise de normalidade foi baseada nesse teste e do total de 30 variáveis apenas 2 apresentaram normalidade univariada. Segundo Hair et al. (2009, p. 322), não há teste exato para normalidade multivariada, mas pesquisadores testam a normalidade univariada e, na ausência desta, diz-se que não há também normalidade multivariada, que é um pressuposto de várias técnicas de análise multivariada de dados, inclusive a modelagem por Equações Estruturais. Nesse caso, o resultado reforça a decisão de utilizar o software Smart PLS para a aplicação de métodos estatísticos multivariados, uma vez que o PLS é um método estatístico não paramétrico, que não requer que os dados sejam distribuídos com normalidade (Hair et al., 2014).

\section{Perfil da Amostra}

Para iniciar o processo de análise, foi necessário verificar quais participantes não responderam a todas as perguntas do questionário ou que responderam a mesma alternativa para todas as perguntas. Esses questionários foram desconsiderados da análise, totalizando dez respostas excluídas. O tamanho final da amostra foi de 118 questionários válidos.

Em relação ao gênero dos respondentes, notou-se que o número de homens e mulheres respondentes ficou relativamente equilibrado. $\mathrm{O}$ gênero masculino contou com 52 respondentes, equivalente a $44,06 \%$ da amostra, enquanto o gênero feminino obteve 66 respondentes, correspondendo a 55,93\% do total.

Pode-se afirmar, de acordo com os dados obtidos em relação à idade, que a maioria dos pesquisados está na faixa etária dos 16 aos 24 anos, correspondendo a $39,83 \%$ dos respondentes. Já 35,59\% dos participantes afirmaram pertencer à faixa etária de 25 a 34 anos, 11,02\% têm idade entre 35 e 44 anos e 7,63\% estão entre 45 a 59 anos. Apenas 7 entrevistados (5,93\%) afirmaram ter mais de 60 anos.

Grande parte dos respondentes possui ensino superior completo, representando $38,14 \%$ da amostra. Com o segundo maior percentual aparecem os respondentes com nível superior incompleto, correspondendo a $35,59 \%$ do total. Enquanto isso, 11,86\% dos entrevistados afirmaram ter ensino médio completo, 9,32\% declararam ter ensino médio incompleto e $4,24 \%$ ensino fundamental completo. Apenas um respondente $(0,85 \%)$ tem ensino fundamental incompleto.

\section{Análise da Unidimensionalidade dos Construtos}

A unidimensionalidade dos construtos foi verificada através da Análise Fatorial Exploratória (AFE), e dois testes foram utilizados para verificar a adequação da técnica de AFE, o Teste de Esfericidade de 
Relações entre Dimensões da Experiência, Satisfação, Recomendação e Intenção de Retornar: A Percepção de Participantes de Evento Cultural Resumo

Bartlett (TEB), que demonstra a existência de relações significativas entre os itens e testa a hipótese nula de que não há correlação significativa entre os itens (Gosling, 2001) e o Kaiser-Meyer-Olkin (KMO). O nível de significância do Teste TEB deve ser inferior a $1 \%$.

A medida Kaiser-Meyer-Olkin (KMO) indica quanto da variância dos dados pode ser atribuído a um fator comum, com variação entre 0 e 1 (Madureira, 2012). De acordo com Hair et al. (2005), os parâmetros para a medida KMO de adequação da amostra são, em ordem crescente: até 0,50 - inaceitável; acima de 0,60 - regular; acima de 0,70 - boa; acima de 0,80 - muito boa; e acima de 0,90 excelente.

A tabela 1 apresenta os dados obtidos com a análise da unidimensionalidade. Todos os construtos foram considerados significantes de acordo com o TEB, e considerados regulares ou bons de acordo com o KMO.

Tabela 1 - Análise da unidimensionalidade dos construtos - resultados da Análise Fatorial Exploratória por construto

\begin{tabular}{|c|c|c|c|}
\hline & Dimensões / Itens & Loadings & KMO e Esferecidade de Bartlett \\
\hline \multicolumn{4}{|c|}{ Hedonismo - Adaptado de Kim, Ritchie e Mccormick (2010) } \\
\hline $\mathrm{H} 1$ & $\begin{array}{l}\text { Sentiu-se entusiasmado por viver uma nova } \\
\text { experiência }\end{array}$ & 0,757 & \multirow{4}{*}{$\begin{array}{c}\text { Kaiser-Meyer-Olkin Measure of } \\
\text { Sampling Adequacy : 0,729 } \\
\text { Bartlett's Test of Sphericity: Sig. } \\
0,000\end{array}$} \\
\hline $\mathrm{H} 2$ & Se jogou na experiência & 0,851 & \\
\hline $\mathrm{H} 3$ & $\begin{array}{c}\text { Sentiu que realmente desfrutou bastante dessa } \\
\text { experiência cultural }\end{array}$ & 0.840 & \\
\hline $\mathrm{H} 4$ & Foi uma experiência emocionante & 0,879 & \\
\hline \multicolumn{4}{|c|}{ Novidade - Adaptado de Kim, Ritchie e Mccormick (2010) } \\
\hline N1 & Foi uma experiência única em sua vida & 0,879 & \multirow{4}{*}{$\begin{array}{c}\text { Kaiser-Meyer-Olkin Measure of } \\
\text { Sampling Adequacy : } 0,772 \\
\text { Bartlett's Test of Sphericity: Sig. } \\
0,000\end{array}$} \\
\hline $\mathrm{N} 2$ & Foi uma experiência incomparável & 0,894 & \\
\hline N3 & Foi uma experiência diferente das anteriores & 0,855 & \\
\hline N4 & Vivenciou algo novo & 0,802 & \\
\hline \multicolumn{4}{|c|}{ Cultura local - Adaptado de Kim, Ritchie e Mccormick (2010) } \\
\hline CL1 & Teve boas impressões sobre as pessoas do evento & 0,852 & \multirow{3}{*}{$\begin{array}{c}\text { Kaiser-Meyer-Olkin Measure of } \\
\text { Sampling Adequacy : 0,642 } \\
\text { Bartlett's Test of Sphericity: Sig. } \\
0,000\end{array}$} \\
\hline CL2 & Experimentou de perto a cultura local & 0,71 & \\
\hline CL3 & As pessoas foram receptivas e amistosas & 0,854 & \\
\hline \multicolumn{4}{|c|}{ Renovação - Adaptado de Kim, Ritchie e Mccormick (2010) } \\
\hline R1 & Experimentou uma sensação de desprendimento & 0,789 & \multirow{4}{*}{$\begin{array}{c}\text { Kaiser-Meyer-Olkin Measure of } \\
\text { Sampling Adequacy : 0,779 } \\
\text { Bartlett's Test of Sphericity: Sig. } \\
0,000\end{array}$} \\
\hline $\mathrm{R} 2$ & Experimentou uma sensação de liberdade & 0,859 & \\
\hline R3 & Foi revigorante & 0,936 & \\
\hline R4 & Foi revitalizante & 0,934 & \\
\hline \multicolumn{4}{|c|}{ Significância - Adaptado de Kim, Ritchie e Mccormick (2010) } \\
\hline $\mathrm{S} 1$ & Vivenciou algo significativo & 0,869 & \multirow{3}{*}{$\begin{array}{c}\text { Kaiser-Meyer-Olkin Measure of } \\
\text { Sampling Adequacy : 0,662 } \\
\text { Bartlett's Test of Sphericity: Sig. } \\
0,000\end{array}$} \\
\hline $\mathrm{S} 2$ & Realizou algo importante & 0,882 & \\
\hline S3 & Aprendeu mais sobre si mesmo(a) & 0,753 & \\
\hline \multicolumn{4}{|c|}{ Envolvimento - Adaptado de Kim, Ritchie e Mccormick (2010) } \\
\hline E1 & Visitou um lugar que você queria muito conhecer & 0,797 & \multirow{2}{*}{$\begin{array}{l}\text { Kaiser-Meyer-Olkin Measure of } \\
\text { Sampling Adequacy : 0,593 }\end{array}$} \\
\hline E2 & Aproveitou atividades que queria muito realizar & 0,882 & \\
\hline
\end{tabular}


Relações entre Dimensões da Experiência, Satisfação, Recomendação e Intenção de Retornar: A Percepção de Participantes de Evento Cultural Resumo

\begin{tabular}{|c|c|c|c|}
\hline E3 & $\begin{array}{c}\text { Estava muito interessado(a) nas principais atividades } \\
\text { desse evento cultural }\end{array}$ & 0,699 & $\begin{array}{l}\text { Bartlett's Test of Sphericity: Sig. } \\
0,000\end{array}$ \\
\hline \multicolumn{4}{|c|}{ Conhecimento - Adaptado de Kim, Ritchie e Mccormick (2010) } \\
\hline $\mathrm{C} 1$ & $\begin{array}{l}\text { O evento lhe proporcionou oportunidade para } \\
\text { explorar a cidade }\end{array}$ & 0,85 & \multirow{3}{*}{$\begin{array}{c}\text { Kaiser-Meyer-Olkin Measure of } \\
\text { Sampling Adequacy : 0,709 } \\
\text { Bartlett's Test of Sphericity: Sig. } \\
0,000\end{array}$} \\
\hline $\mathrm{C} 2$ & $\begin{array}{c}\text { O evento lhe proporcionou oportunidade para } \\
\text { conhecer e aprender }\end{array}$ & 0,916 & \\
\hline $\mathrm{C} 3$ & $\begin{array}{l}\text { O evento lhe proporcionou oportunidade de contato } \\
\text { com uma nova cultura }\end{array}$ & 0,931 & \\
\hline \multicolumn{4}{|c|}{ Intenção de retorno - Adaptada de Ajzen e Fishbein (1980) } \\
\hline I1 & Tem vontade de participar do evento no próximo ano & 0,903 & \multirow{4}{*}{$\begin{array}{c}\text { Kaiser-Meyer-Olkin Measure of } \\
\text { Sampling Adequacy : 0,758 } \\
\text { Bartlett's Test of Sphericity: Sig. } \\
0,000\end{array}$} \\
\hline $\mathrm{I} 2$ & Vai tentar participar do evento no próximo ano & 0,897 & \\
\hline I3 & $\begin{array}{c}\text { Vai se programar para participar do evento no } \\
\text { próximo ano }\end{array}$ & 0,911 & \\
\hline I4 & $\begin{array}{l}\text { Vai se comprometer a participar do evento no } \\
\text { próximo ano }\end{array}$ & 0,812 & \\
\hline
\end{tabular}

Fonte: Processamento dos dados.

\section{Análise do Modelo de Mensuração}

Para a análise do modelo de mensuração, segundo recomendações de Hair et al. (2014), realizou-se a análise do Alpha de Cronbach, confiabilidade composta, validade convergente e validade discriminante. O modelo testado é o da Figura 2. Note-se que os construtos Conhecimento e Envolvimento foram modelados juntos, pois houve problemas com a validade discriminante. Além disso, conforme evidenciado na fig. 2 , o construto Experiência Turística Memorável é de segunda ordem, sendo modelado de forma hierárquica, segundo propõem Hair et al. (2014). Fica claro, também pela Fig. 2, que as dimensões desse construto Experiência Turística Memorável propostas na literatura e aqui testadas compõem, formam tal construto, e não o refletem. Posto de outra forma, as dimensões apontam para o construto. 
Relações entre Dimensões da Experiência, Satisfação, Recomendação e Intenção de Retornar: A Percepção de Participantes de Evento Cultural Resumo

Figura 2 - Modelo de mensuração

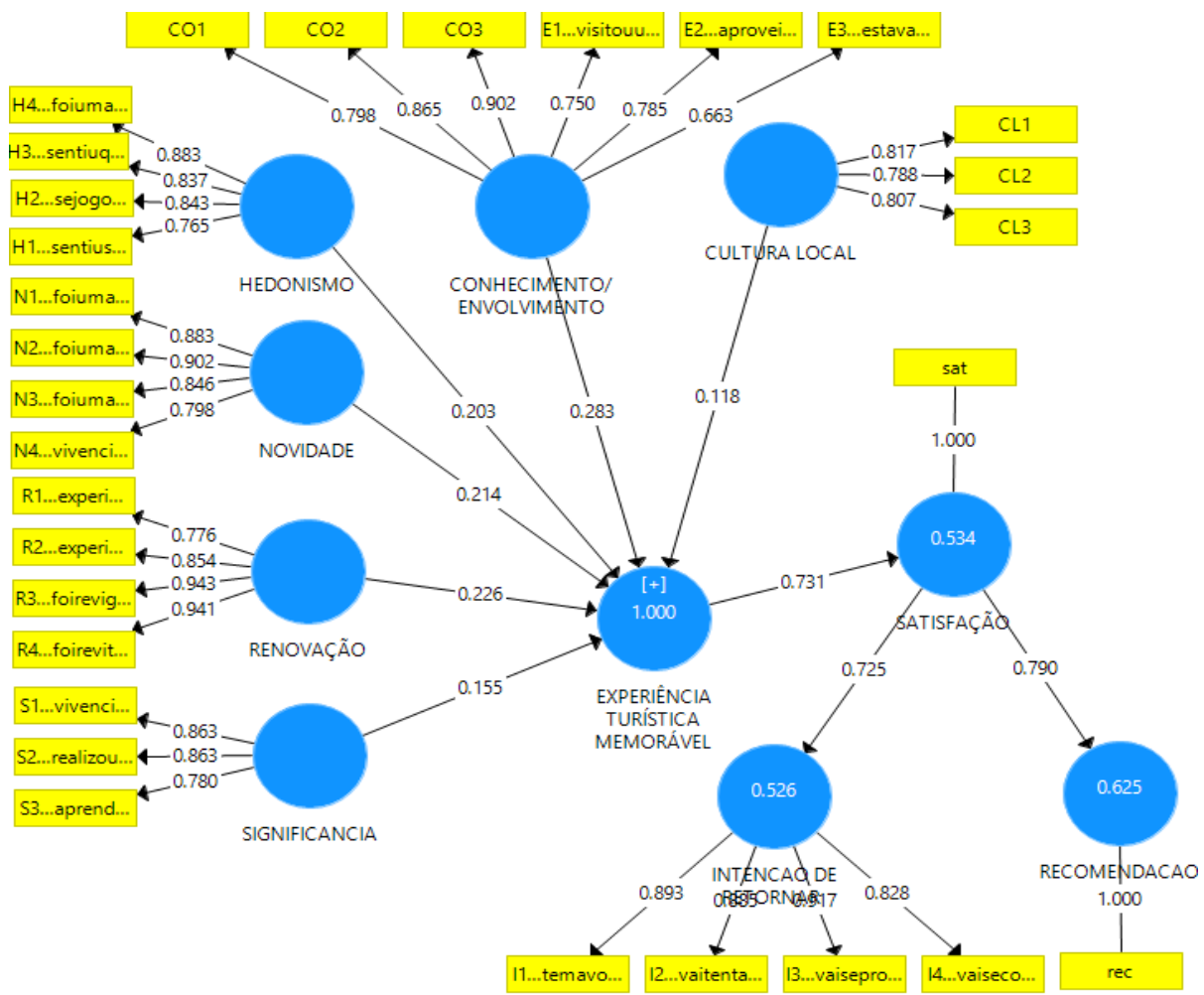

Fonte: Elaborado pelos autores (2016)

A Tabela 2 evidencia os critérios de corte propostos por Henseler et al. (2009), Souza (2013, p. 63) e Hair et al. (2014).

Tabela 2 - Critérios de avaliação dos construtos quanto ao modelo de mensuração

\begin{tabular}{|c|c|}
\hline Medida & Parâmetro de aceitação \\
\hline \multicolumn{2}{|r|}{ Confiabilidade } \\
\hline Confiabilidade composta & \multirow{3}{*}{$\begin{array}{c}>0,95 \text { (indesejado) } \\
>0,700 \text { a } 0,900-\text { recomendável } \\
>0,6 \text { a } 0,7 \text { aceitável em estudos exploratórios } \\
<0,600 \text { (inaceitável) } \\
\text { Igual à confiabilidade composta } \\
>0,708 \text { (recomendável) } \\
<0,4 \text { e } 0,7 \text { (considerar a exclusão, caso aumente a } \\
\text { confiabilidade composta e a AVE) }\end{array}$} \\
\hline Alfa de Cronbach & \\
\hline Cargas Externas & \\
\hline \multicolumn{2}{|r|}{ Validade Convergente } \\
\hline Variância explicada (AVE) & $>50 \%$ \\
\hline Comunalidade & $>0,500$ \\
\hline \multicolumn{2}{|r|}{ Validade Discriminante } \\
\hline Fornell e Larcker & $\begin{array}{l}\text { A raiz quadrada da AVE de cada construto deve ser maior } \\
\text { que a sua maior correlação com qualquer outro construto }\end{array}$ \\
\hline
\end{tabular}

Fonte: Henseler et al. (2009), Souza (2013, p. 63) e Hair et al. (2014). 
A análise do Alfa de Cronbach para a verificação da confiabilidade não considera os erros nos indicadores (Hair et al., 2005), e assume que todos os indicadores são igualmente confiáveis (Henseler et al., 2009). Por outro lado, a confiabilidade composta privilegia indicadores conforme sua confiabilidade, proporcionando uma maior composição confiável (Henseler et al., 2009). Desse modo, a análise da confiabilidade composta é considerada mais fidedigna do que o Alfa de Cronbach (Henseler et al., 2009; Hair et al., 2005;
2014). Os parâmetros para avaliação da confiabilidade composta indicados pelos autores é usualmente interpretado igual aos do Alfa de Cronbach.

A tabela 3 demonstra que os valores do Alfa de Cronbach e da confiabilidade composta apresentaram-se ajustados para todos os construtos. Note-se que Satisfação e Recomendação não são construtos, tendo sido medidos apenas por um indicador. Portanto, não há que se falar em confiabilidade.

Tabela 3 - Alpha de Cronbach e confiabilidade composta

\begin{tabular}{|l|c|c|}
\hline \multicolumn{1}{|c|}{ Construtos } & $\begin{array}{c}\text { Alpha de } \\
\text { Cronbach }\end{array}$ & $\begin{array}{c}\text { Confiabilidade } \\
\text { Composta }\end{array}$ \\
\hline CONHECIMENTO/ENVOLVIMENTO & 0,883 & 0,912 \\
\hline CULTURA LOCAL & 0,731 & 0,846 \\
\hline HEDONISMO & 0,852 & 0,901 \\
\hline INTENÇÃO DE RETORNAR & 0,904 & 0,933 \\
\hline NOVIDADE & 0,880 & 0,918 \\
\hline RENOVAÇÃO & 0,903 & 0,933 \\
\hline SIGNIFICÂNCIA Fonte: Saída do software SmartPLS. & 0,874 \\
\hline \multicolumn{2}{|c|}{}
\end{tabular}

A validade convergente implica que os indicadores representam o conceito de um mesmo construto (Henseler et al., 2009). A validade convergente (Tab. 4) foi avaliada a partir da variância média extraída por construto (AVE), que equivale a mensurar a comunalidade entre eles, e das cargas externas.

Netemeyer et al. (2014) sugerem que as estimativas da AVE sejam superiores a 0,45 , e as cargas externas de todos os indicadores devem ser estatisticamente significativas e superiores ou iguais a 0,708 ( 0,70 é considerado aceitável por ser suficientemente perto de 0,708). Indicadores com cargas externas entre 0,40 e 0,70 devem ser eliminados apenas se sua eliminação levar a um aumento da confiabilidade composta ou da AVE (Hair et al., 2014).

Os dados apresentados na tabela 4, que foram obtidos com a análise dos dados no software SmartPLS, mostram que todos os construtos apresentam AVE superiores a 0,45 e, portanto, estão dentro do recomendável. Além disso, todas as cargas externas são significativas e acima do valor crítico de 0,708. Note-se que as AVE de Satisfação e de Recomendação são iguais à unidade $(1,000)$, visto que ambas só têm um único indicador. 
Relações entre Dimensões da Experiência, Satisfação, Recomendação e Intenção de Retornar: A Percepção de Participantes de Evento Cultural Resumo

Tabela 4 - Validade convergente

\begin{tabular}{|l|c|}
\hline \multicolumn{1}{|c|}{ Construtos } & AVE \\
\hline CONHECIMENTO/ENVOLVIMENTO & 0,636 \\
\hline CULTURA LOCAL & 0,647 \\
\hline HEDONISMO & 0,694 \\
\hline INTENÇÃO DE RETORNAR & 0,777 \\
\hline NOVIDADE & 0,736 \\
\hline RENOVAÇÃO & 0,777 \\
\hline SIGNIFICÂNCIA & 0,699 \\
\hline RECOMENDAÇÃO & 1,000 \\
\hline SATISFAÇÃO & 1,000 \\
\hline
\end{tabular}

Fonte: Saída do software SmartPLS.

Para testar a validade discriminante foi usado o critério de Fornell e Larcker (Hair et al., 2014). Esse critério estabelece que o construto deve compartilhar mais variância com seus indicadores do que com os outros construtos do modelo. Assim, a raiz quadrada da AVE de cada construto deve ser maior do que a maior correlação com cada construto (Hair et al., 2014). Se a correlação ao quadrado for inferior às AVEs dos construtos quando comparados, há indícios de que os construtos são distintos e possuem validade discriminante (Madureira, 2012).

Inicialmente, o modelo testado tinha as 7 dimensões da MTE, modeladas como distintas. No entanto, houve problemas na validade discriminante entre envolvimento e conhecimento. Dessa forma, foi testado um modelo alternativo, em que conhecimento e envolvimento foram tratados como uma única dimensão.

Os resultados obtidos pela análise dos dados no SmartPLS são apresentados na tabela 5, comprovando a validade discriminante entre os construtos do modelo. Note-se que, como o modelo é hierárquico, o construto Experiência Memorável é de segunda ordem, com repetição de indicadores de primeira ordem. Segundo Hair et al. (2014), tal fato faz com que não haja razão para se testar a validade discriminante desse construto, razão pela qual optou-se por excluí-lo da tabela 5.

Tabela 5 - Validade discriminante

\begin{tabular}{|l|r|l|l|l|l|l|l|l|l|}
\hline & $\begin{array}{l}\text { Conhec/ } \\
\text { envolv }\end{array}$ & $\begin{array}{l}\text { Cult } \\
\text { local }\end{array}$ & $\begin{array}{l}\text { Hedo- } \\
\text { nismo }\end{array}$ & $\begin{array}{l}\text { Intenção } \\
\text { de } \\
\text { Retornar }\end{array}$ & $\begin{array}{l}\text { Novi- } \\
\text { dade }\end{array}$ & $\begin{array}{l}\text { Recomen } \\
\text { dação }\end{array}$ & $\begin{array}{l}\text { Reno- } \\
\text { vação }\end{array}$ & $\begin{array}{l}\text { Satis- } \\
\text { fação }\end{array}$ & $\begin{array}{l}\text { Signifi- } \\
\text { cância }\end{array}$ \\
\hline $\begin{array}{l}\text { Conhecimento/Envol } \\
\text { vimento }\end{array}$ & $\mathbf{0 , 7 9 8}$ & & & & & & & & \\
\hline Cultura Local & 0,595 & $\mathbf{0 , 8 0 4}$ & & & & & & & \\
\hline Hedonismo & 0,596 & 0,441 & $\mathbf{0 , 8 3 3}$ & & & & & & \\
\hline Intenção de Retornar & 0,573 & 0,527 & 0,571 & $\mathbf{0 , 8 8 1}$ & & & & & \\
\hline Novidade & 0,724 & 0,641 & 0,659 & 0,539 & $\mathbf{0 , 8 5 8}$ & & & & \\
\hline Recomendaçao & 0,542 & 0,508 & 0,524 & 0,845 & 0,514 & $\mathbf{1 , 0 0 0}$ & & & \\
\hline Renovação & 0,605 & 0,461 & 0,700 & 0,557 & 0,559 & 0,509 & $\mathbf{0 , 8 8 1}$ & & \\
\hline Satisfação & 0,620 & 0,510 & 0,637 & 0,725 & 0,588 & 0,790 & 0,629 & $\mathbf{1 , 0 0 0}$ & \\
\hline Significância & 0,640 & 0,590 & 0,694 & 0,534 & 0,692 & 0,498 & 0,727 & 0,625 & $\mathbf{0 , 8 3 6}$ \\
\hline
\end{tabular}

Fonte: Saída do software SmartPLS. 


\section{ANÁLISE DO MODELO ESTRUTURAL}

$\mathrm{Na}$ análise do modelo estrutural foram analisados os coeficientes de caminho, os coeficientes de determinação $\left(R^{2}\right.$ e $R^{2}$ ajustado) e por último o SRMR. O modelo foi rodado no bootstraping com uma subamostra de 5000 .

Figura 3 - Modelo estrutural

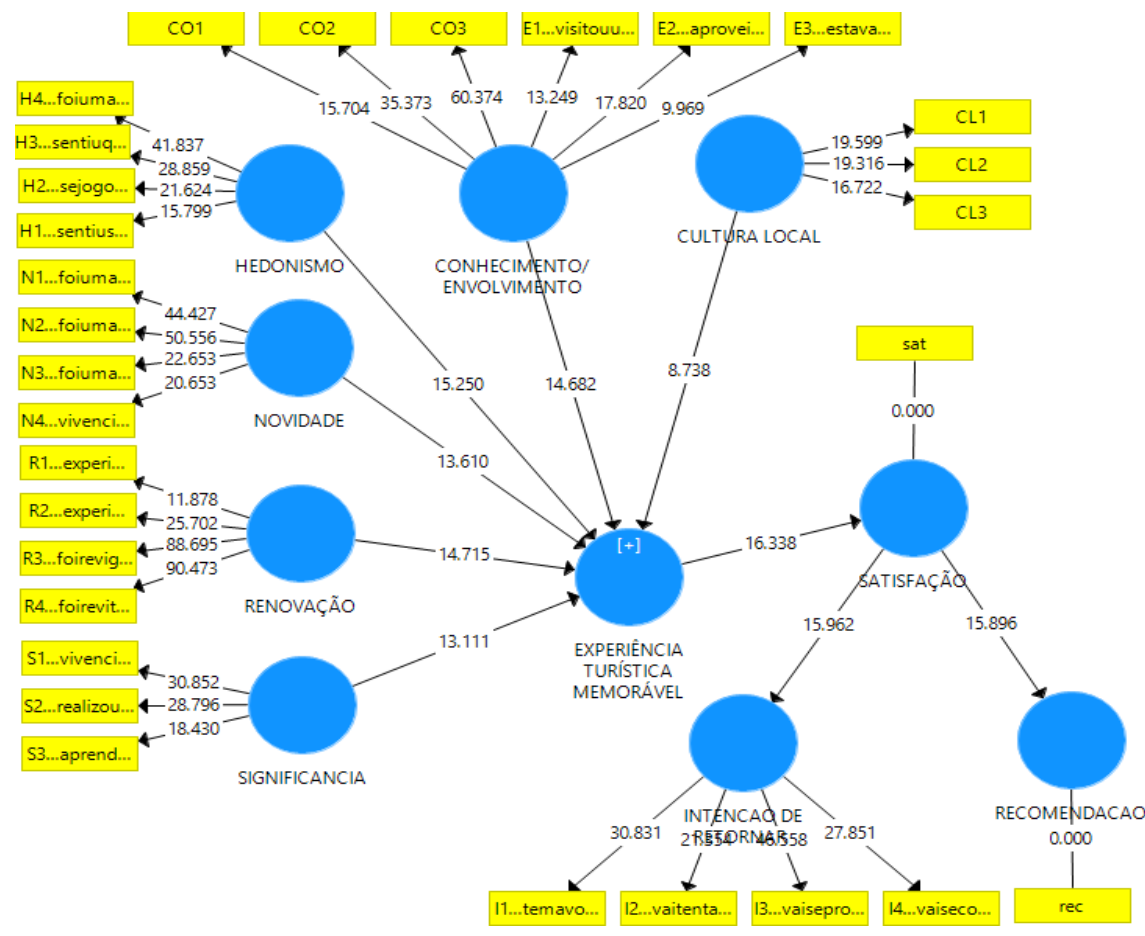

Fonte: Elaborado pelos autores (2016).

Os coeficientes de caminho representam as relações hipotéticas entre os construtos. Para identificar se um coeficiente é significativo, pode ser usado: $\mathrm{p}$-valor, intervalo de confiança e teste $\mathrm{t}$, todos os testes levam à mesma conclusão. Os valores do teste $\mathrm{t}$ devem ser superiores ao valor crítico, que é 2,58 para o nível de significância de $1 \%$, para que o coeficiente seja significativo. No modelo estrutural, um coeficiente de caminho pode ser interpretado em relação ao outro - se um coeficiente de caminho é maior do que outro, o seu efeito sobre a variável latente endógena é maior (Hair et al., 2014).

$\mathrm{O}$ resultado dos coeficientes de caminho do modelo estrutural (Tabela 6) evidenciam que todas as hipóteses propostas foram suportadas, considerandose que as hipóteses sobre a influência de conhecimento e de envolvimento foram testadas como uma única hipótese, já que não houve validade discriminante entre esses dois construtos, no modelo de mensuração. 
Relações entre Dimensões da Experiência, Satisfação, Recomendação e Intenção de Retornar: A Percepção de Participantes de Evento Cultural Resumo

Tabela 6 - Coeficientes de caminho do modelo estrutural

\begin{tabular}{|l|c|c|}
\hline \multicolumn{1}{|c|}{ Construtos } & Estatística $t$ & $p$-valor \\
\hline $\begin{array}{l}\text { CONHECIMENTO/ENVOLVIMENTO } \rightarrow \text { EXPERIÊNCIA } \\
\text { TURÍSTICA MEMORÁVEL }\end{array}$ & 14,682 & 0,000 \\
\hline $\begin{array}{l}\text { CULTURA LOCAL } \rightarrow \text { EXPERIÊNCIA TURÍSTICA } \\
\text { MEMORÁVEL }\end{array}$ & 8,738 & 0,000 \\
\hline $\begin{array}{l}\text { HEDONISMO } \rightarrow \text { EXPERIÊNCIA TURÍSTICA } \\
\text { MEMORÁVEL }\end{array}$ & 15,250 & 0,000 \\
\hline NOVIDADE $\rightarrow$ EXPERIÊNCIA TURÍSTICA MEMORÁVEL & 13,610 & 0,000 \\
\hline $\begin{array}{l}\text { SIGNIFICÂNCIA } \rightarrow \text { EXPERIÊNCIA TURÍSTICA } \\
\text { MEMORÁVEL }\end{array}$ & 13,111 & 0,000 \\
\hline $\begin{array}{l}\text { RENOVAÇÃO } \rightarrow \text { EXPERIÊNCIA TURÍSTICA } \\
\text { MEMORÁVEL }\end{array}$ & 14,715 & 0,000 \\
\hline $\begin{array}{l}\text { EXPERIÊNCIA TURÍSTICA MEMORÁVEL } \rightarrow \\
\text { SATISFAÇÃO }\end{array}$ & 16,338 & 0,000 \\
\hline SATISFAÇ̃̃O $\rightarrow$ INTENÇÃO DE RETORNAR & 15,962 & 0,000 \\
\hline SATISFAÇÃO $\rightarrow$ RECOMENDAÇÃO & 15,896 & 0,000 \\
\hline
\end{tabular}

Fonte: Saída do software SmartPLS através do método Bootstrapping.

O valor de $\mathrm{R}^{2}$, coeficiente de determinação, indica a capacidade preditiva do modelo e varia entre 0 e 1 , sendo os valores mais próximos de 1 indicativos de maior poder de previsão. Os coeficientes de determinação devem ser avaliados pelos parâmetros de valores de 0,19; 0,33 e 0,67, sendo, respectivamente, fracos, moderados e substanciais (Henseler et al., 2009; Hair et al., 2014).

De acordo com os valores obtidos pela análise dos dados no software SmartPLS, tanto $\mathrm{R}^{2}$ quanto $\mathrm{R}^{2}$ ajustado são considerados moderados para os construtos endógenos.

Tabela 7 - Coeficiente de determinação

\begin{tabular}{|l|c|c|}
\hline \multicolumn{1}{|c|}{ Construtos } & $\mathbf{R}^{\mathbf{2}}$ & $\begin{array}{c}\mathbf{R}^{\mathbf{2}} \\
\text { Ajustado }\end{array}$ \\
\hline INTENÇÃO DE RETORNAR & 0,526 & 0,522 \\
\hline RECOMENDAÇÃO & 0,625 & 0,622 \\
\hline SATISFAÇÃO & 0,534 & 0,530 \\
\hline
\end{tabular}

Fonte: Saída do software SmartPLS.

O SRMR é definido como a diferença entre a correlação observada e a correlação prevista. Um valor até 0,10 ( $\mathrm{Hu}$ e Bentler, 1999) é considerado bom. Portanto, o valor

\section{CONCLUSÃO}

A pesquisa resultou em análises quantitativas que atenderam aos objetivos do trabalho. De acordo com os resultados do obtido com a análise dos dados, através do software SmartPLS (SRMR=0,103), é considerado adequado, evidenciando o bom ajuste do modelo proposto.

survey, considerando o valor das médias das notas dos construtos, a dimensão hedonismo teve a maior média. As dimensões avaliadas com notas mais 
baixas no survey, considerando as médias totais dos construtos, pelos participantes da Virada, foram novidade e significância $(5,36)$. A novidade no presente contexto é a busca por novas experiências, originais e incomparáveis com experiências anteriores dos participantes (Dunman \& Mattila, 2005). Já a dimensão de significância refere-se ao sentido que o evento tem na vida dos participantes, podendo gerar mudanças pessoais para eles (Noy, 2004).

De maneira geral os participantes se mostraram satisfeitos com o evento. De acordo com o survey, a média geral do nível de satisfação foi alta com pontuação de 7,68 em uma escala de 0 (inteiramente insatisfeito) a 10 (inteiramente satisfeito).

A intenção de retorno respondida pelos participantes da Virada no survey. De acordo com os resultados dessa escala, a intenção de retorno apresentou a segunda maior nota das dimensões do questionário com a nota de 7,91 em uma escala de 0 (discordo totalmente) a 10 (concordo totalmente). Entretanto, a escala foi gradativa e demonstrou que os participantes concordam mais com o fato de que têm vontade de participar do evento nas próximas edições do que realmente se comprometem a participar do evento nas próximas edições.

Os participantes demonstraram que existem grandes chances de recomendar o evento para pessoas próximas. Ao analisar o resultado final do survey, o construto de recomendação boca a boca apresentou a maior nota entre as dimensões avaliadas pelos participantes. A média da nota total da pergunta de recomendação foi de $8,25 \mathrm{em}$ uma escala de 0 (chance muito baixa) a 10 (chance muito alta). A recomendação boca a boca é formada a partir de várias observações referentes a uma experiência. Um consumidor pode ter uma opinião sobre um serviço que engloba aspectos positivos e negativos, e, ao indicar o serviço para alguém, irá transmitir os aspectos mais relevantes em sua recomendação (Wang, 2011). Sendo assim, se o participante ficou mais satisfeito com o evento, a chance de recomendá-lo também é maior.

Nota-se, também, que a dimensão hedonismo foi a mais impactante para uma experiência memorável e a cultura local a menos impactante. Como o evento é local, é fácil perceber que os participantes são, em sua maioria, residentes e, portanto, já conhecedores da cultura local. Isso, portanto, não tem tanta influência na memorabilidade do evento, como as demais dimensões avaliadas.

Além da relevância acadêmica, ao se fazer o teste de um modelo em contexto de eventos, adaptando escalas anteriores, é possível perceber que todas as dimensões da experiência memorável foram importantes na satisfação do participante e na intenção deste de recomendar e participar novamente. Assim, apesar de não generalizável, esse resultado pode orientar gestores da cidade para novos eventos.

Uma limitação foi a restrição geográfica e temporal da amostra. O evento teve duração total de 24 horas e aconteceu em mais de 420 locais em Belo Horizonte. Entretanto, a pesquisa foi realizada apenas em seis locais, pontos de referência das grandes atrações, em diferentes horários durante o evento. Os resultados gerados nesse estudo também não podem ser generalizados para outros eventos ou contextos por causa das especificidades da Virada Cultural.

$\mathrm{O}$ presente estudo buscou dar continuidade a estudos relacionados ao campo ainda em fase de exploração para o marketing, a experiência de consumo, dentro de um contexto que começa a entender a importância dessa dimensão em eventos culturais. A principal sugestão é a realização de pesquisas que explorem outros construtos mais afinados a eventos, como questões em que os participantes possam avaliar a infraestrutura dedicada ao evento em tela. Além disso, estudar os antecedentes de experiência turística memorável, como motivações específicas aplicadas aos eventos, também pode ser academicamente relevante. Afinal, 
compreender o que leva as pessoas a participar principalmente de eventos culturais faz com que mais indivíduos se interessem por esse tipo de experiência, além de possibilitar a execução de mais eventos com esse caráter. Isso seria útil para os órgãos públicos ligados à gestão das

\section{REFERÊNCIAS}

Ajzen, I., \& Fishbein, M. (1980). Understanding attitudes and predicting social behavior. Englewood Cliffs, NJ: Prentice-Hall.

Brakus, J. J., Schmitt, B. H., \& Zarantonello, L. (2009). Brand experience: What is it? How is it measured? Does it affect loyalty?. Journal of Marketing, 73, 52-68.

Bruner, E. (1991). Transformation of self in tourism. Annals of Tourism Research, 18(2), 238-250.

Chen, C., \& Chen, F. (2010). Experience quality, perceived value, satisfaction and behavioral intentions for heritage tourists. Tourism Management, 31, 29-35.

Cozby, P. C. (2003). Métodos de pesquisa em ciências do comportamento. São Paulo: Atlas.

Creswell, J. W. (2007). Projeto de pesquisa: métodos qualitativo, quantitativo e misto. Porto Alegre: Artmed.

Cronin, J. J. J., \& Taylor, S. A. (1992). Measuring service quality: A reexamination and extension. The Journal of Marketing, 56(3), 55-68.

Davis, S., \& Longoria, T. (2003). Harmonizing your touchpoints. Brand Packaging Magazine, 1-4. cidades. Para as empresas, esse envolvimento das pessoas com eventos culturais gera uma oportunidade de patrocínio nesse tipo de evento e relação direta entre consumidor e marca em um contexto diferente.

Dunman, T., \& Mattila, A. S. (2005). The role of affective factors on perceived cruise vacation value. Tourism Management, 26, 311-323.

East, R., Hammond, K. A., \& Wright, M. (2007). The relative incidence of positive and negative word of mouth: A multi-category study. International Journal of Research in Marketing, 24(2), 175-184.

Farber, M. E., \& Hall, T. E. (2007). Emotion and environment: Visitors' extraordinary experiences along the Dalton Highway in Alaska. Journal of Leisure Research, 39 (2), 248-270.

G1 MG. (2014). Virada Cultural movimenta diversos espaços de Belo Horizonte. Acesso em 3 out. de 2014 em: << http://g1.globo.com/minasgerais/noticia/2014/08/virada-culturalmovimenta-diversos-espacos-de-belohorizonte.html $>$.

Gennep, A. V. (2011). Os ritos de passagem. $3^{\text {a }}$ Ed. Vozes: Petrópolis.

Getz, D. (2007). Event studies: Theory, research and policy for planned events. Grã-Bretanha: Elsevier.

Gilmore, J. H., \& Pine II, B. J. (1999). O espetáculo dos negócios. Rio de Janeiro: Campus. 
Relações entre Dimensões da Experiência, Satisfação, Recomendação e Intenção de Retornar: A Percepção de Participantes de Evento Cultural Resumo

Giorgi, L., Sassatelli, M., e Delanty, G. (Eds.). (2011). Festivals and the cultural public sphere. Reino Unido: Routledge.

Hair, J., Anderson, R. E., Tatham, R. L., \& Black, W. C. (2005). Análise multivariada de dados. Porto Alegre: Bookman.

Hair, J., Black, W. C., Babin, B., Anderson, R. E., \& Tatham, R. L. (2009). Análise multivariada de dados. Porto Alegre: Bookman.

Hair, J., Hult, G. T. M., Ringle, C. M., \& Sarstedt, M. (2014). A primer on partial least squares structural equation modeling (PLS-SEM). Los Angeles: Sage Publications.

Hede, A. M., \& Kellet, P. (2011). Marketing communications for special events: Analyzing managerial practice, consumer perceptions and preferences. European Journal of Marketing, 45(6), 987-1001.

Hosany, S., \& Gilbert, D. (2009). Measuring tourists' emotional experiences toward hedonic holiday destinations. Journal of Travel Research, 48, 1-14.

Howard, E. A., Tinsley, J. A. H., Tinsley, D. J., \& Holt, M. S. (1993). Attributes of leisure and work experiences. Journal of Counseling Psychology, 40(4), 447-55.

Kim, J-H. (2009). Development of a scale to measure memorable tourism experiences. (Tese de Doutoramento não publicada). Indiana University.

Kim, J-H., Ritchie, J. R. B., \& Mccormick, B. (2010). Development of a scale to measure memorable tourism experiences. Journal of Travel Research, 51(1), 12-25.
Kim, S., \& Byon, K. (2013). Social motivations and consumption behavior of spectators attending a Formula One Motorracing Event social behavior and personality. Social behavior and personality, 41(8), 1359-1378.

McGrath, M. A. (2004). The evolution, transformation, and demise of a ritual: the case of May Day. In: Otnes, C. C., \& Lowrey, T. M. (orgs.) Contemporary consumption rituals: a research anthology (pp. 83-98). Mahwah/New Jersey: Lawrence Erlbaum Associates.

Malhotra, N. K. (2001). Pesquisa de marketing: uma orientação aplicada. Porto Alegre: Bookman.

Moufakkir, O., Pernecky, T. (Eds.). (2015). Ideological, social and cultural aspects of events. Reino Unido: CABI.

Murray, N., Foley, A., \& Lynch, P. (2010). Understanding the tourist experience concept. Acesso em 12 out. 2014 em $<$ http://repository.wit.ie/1543/1/F\%C3\%81I LTE_GO_SL\%C3\%81INTE_UNDERSTA NDING_THE_TOURIST_EXPERIENCE CONCEPT.pdf $>>$

Noy, C. (2004). This trip really changed me: Backpackers' narratives of self-change. Annals of Tourism Research, 31 (1), 78-102.

Oh, H., Fiore, A. M., \& Jeong, M. (2007). Measuring experience economy concepts: Tourism applications. Journal of Travel Research, 46, 119-32.

Oliver, R. L. (1997). Satisfaction: A behavioral perspective on the consumer. Boston: McGraw-Hill.

Oliver, R. L. (1980). A cognitive model of the antecedents and consequences of satisfaction decisions. Journal of Marketing Research, 17(4), 460-469. 
Otto, J. E., \& Ritchie, J. R. B. (1996). The service experience in tourism. Tourism Management, 17 (3), 165-74.

Paiva, R. A. (2015). Eventos e megaeventos: ócio e negócio no turismo. Revista Brasileira de Pesquisa em Turismo. São Paulo, 9(3), pp. 479-499, set./dez.

Pine, B. J., \& Gilmore, J. H. (1998). Welcome to the experience economy. Harvard Business Review, 86(4), 97-105.

Price, S. R. F. (1984) Rituals and power: the Roman Imperial cult in Asia Minor. Great Britain: Cambridge University Press.

Ranaweera, C., \& Jayawardhena, C. (2014). Talk up or criticize? Customer responses to WOM about competitors during social interactions. Journal of Business Research, 67, 2645-2656.

Schmitt, B. (1999). Experiential marketing. Journal of Marketing Management, 15, 56-67.

Virada Cultural de Belo Horizonte. (2014). Saiba mais sobre a Virada Cultural de BH. Acesso em 3 out. 2014 em: << http://www.viradaculturalbh.com.br/noticia s/saiba-mais-sobre-a-virada-cultural-de-bh/ >.

Wang, X. (2011). The effect of unrelated supporting service quality on customer delight, satisfaction, and repurchase intention. Journal of Service Research, 14 (2), 149-167.

Yoon, Y; Uysal, M. (2005). An examination of the effects of motivation and satisfaction on destination loyalty: a structural model. Tourism Management, 26, 45-56. 